\title{
A community survey of asthmatic characteristics
}

\author{
M. L. BURR, A. S. ST. LEGER, CAROL BEVAN, \\ and T. G. MERRETT \\ MRC Epidemiology and Pneumoconiosis Units, Cardiff, and Benenden Chest Hospital, Kent
}

\begin{abstract}
Burr, M. L., St. Leger, A. S., Bevan, Carol, and Merrett, T. G. (1975). Thorax, 30, 663-668. A community survey of asthmatic characteristics. A survey was undertaken among adults aged 20-44 years in a South Wales town. Persons with a history of wheezing with breathlessness and in the absence of a cold were identified by postal questionnaires and seen at a clinic, together with a sample of subjects without these symptoms. The response rates for the first and second stages of the survey were $99.6 \%$ and $91.0 \%$ respectively, and 574 subjects were ultimately seen.

Asthmatic patients (those receiving treatment within the previous year) had some airways obstruction at rest, which increased after exercise. They also had strong allergic tendencies, as shown by personal and family history, skin tests, and serum IgE levels. The ex-asthmatics (those not receiving treatment within the previous year) showed these tendencies to a lesser extent. A larger group gave a history of wheezing but stated that they had never had asthma; in their response to exercise and allergic traits they resembled the control group rather than the asthmatics, and appeared to have the features of chronic bronchitis. Asthma and chronic bronchitis would therefore seem to be distinct clinical entities within the population studied.
\end{abstract}

Asthma is a disorder characterized by airways obstruction which varies in severity over short periods of time, causing episodes of wheezing and breathlessness. Similar features are sometimes associated with chronic bronchitis, and so far, no agreement has been reached about definitions which will distinguish satisfactorily between the two conditions (Porter and Birch, 1971). It has therefore been suggested that they are better regarded as forming part of a single diagnostic entity, chronic obstructive lung disease (Ciba Guest Symposium, 1959; Mitchell and Filley, 1964; Burrows et al., 1965). This concept has been criticized as implying 'diagnostic defeatism' (Scadding, 1971), in that asthma and chronic bronchitis can usually be distinguished fairly easily and probably involve different pathological processes (Ford, 1969). A survey of asthmatic characteristics in the community was therefore undertaken in order to clarify the clinical picture of these diseases.

\section{METHODS}

The names and addresses were obtained of all persons aged 20 to 44 years inclusive, living in a South Wales town and registered with the local general practitioners. A screening questionnaire was sent to a random half of this population enquiring about respiratory symptoms; those who did not reply were sent a second form and visited if necessary.
The subjects were divided initially into two groups on the basis of their answers to the screening questionnaire. All those who gave a history of wheezing, which had occurred with breathlessness and in the absence of a cold, were contacted for a clinic appointment to be made. The remaining subjects were regarded as the control population, and a 1 in 10 sample was asked to attend the clinic.

In a pilot study it was found that the word 'wheeze' was liable to be misunderstood, so the following definition was included in the questionnaire: 'Wheezing means a whistling sound, whether high- or lowpitched, and however faint'.

At the clinic the subjects were weighed and measured, and a detailed questionnaire was completed. The forced expiratory volume in one second $\left(F E V_{1}\right)$ was measured five times, and the mean of the highest three readings obtained, with the mean of two readings of forced vital capacity (FVC). Each person stepped on and off a 12 in $(30 \mathrm{~cm})$ box in time with a metronome set at $100 /$ minute for 6 minutes (men) or 5 minutes (women). For those who became very breathless during exercise, 2 in $(5 \mathrm{~cm})$ were removed from the height of the box and, if necessary, the rate of stepping was reduced in order to allow them to continue exercising for the full period. The subjects then rested for 5 minutes and repeated the 
lung function tests. An inhalation of salbutamol was given and the tests were carried out again after an interval of 15 minutes. Skin prick tests against common allergens were performed during the resting period and the results were read in the interval.

Blood was taken and IgE was estimated by double antibody radioimmunoassay as described by Nye $e t$ al. (1975), except that the standards and samples were diluted in fetal calf serum and the precipitate was washed three times before being counted. This method estimated IgE levels as low as $0.8 \mathrm{u} / \mathrm{ml}$ with a between-assay variation of $14 \%$; it was introduced in the laboratory during the course of the survey so that results are available only for the 389 subjects seen after this point.

\section{RESULTS}

The screening questionnaire was answered by 3068 subjects, while 11 refused to reply, giving an initial response rate of $99.6 \%$. It was subsequently found that some subjects had replied without indicating that they had moved outside the area and that the questionnaire had been forwarded to them. When they and pregnant women were excluded, a total of 310 men and 321 women were eligible to be seen at the clinic because of their history of wheezing or because they had been selected as controls. Of these, 272 men and 302 women were ultimately seen, so that the response rates for this stage were $87.7 \%$ for men, $94.1 \%$ for women, and $91.0 \%$ overall.

The subjects were classified into four groups as follows:

1. 53 'current asthmatics' who gave a history of wheezing with breathlessness in the absence of a cold, and claimed to have asthma, for which they had taken bronchodilators, steroids or disodium cromoglycate during the previous $12 \frac{\bar{F}}{2}$ months.

2. 52 subjects who also gave a history of wheezing, $\frac{\overline{\bar{N}}}{\bar{N}}$ and claimed to have had asthma, but this had $\vec{\sigma}$ not required treatment during the past $12 \propto$ months. These will be called 'ex-asthmatics'. के

3. 269 subjects who gave a similar history of $\vec{\circ}$ wheezing but denied ever having had asthma. They will be called 'other wheezers'.

4. 200 'controls'. They were a 1 in 10 sample of subjects who denied wheezing and were accepted $x$ as normal.

Table I summarizes some aspects of the clinical history of the subjects, classified as above. A sig- $)$ nificantly higher proportion of asthmatic men and $\omega$ women gave a personal and a family history of allergic $\mathrm{S}$ disorders than did the 'other wheezers' or the control groups. A family history of allergy (that is, asthma, $\mathbb{D}$ hay fever or eczema in any first-degree relative) was $\Phi$ also more common in ex-asthmatic men than in $\overline{0}$ controls.

The control subjects reported less chest infections $\vec{\varphi}$ than the others, especially among the men. A cough or and chronic phlegm, grades 1 and 2 (Medical Research Council Committee on the Aetiology of Chronic Bronchitis, 1965), were more prevalent among the asthmatics and 'other wheezers' than in the othero groups. The proportion of persons who smoked $\frac{\mathrm{O}}{\mathrm{D}}$ cigarettes was highest among the 'other wheezers'. In this group only 38 men $(31.1 \%)$ and 55 womeno $(9.5 \%)$ had consulted a doctor about their wheezing, and of these one-third could not remember the diagnosis. Another third had been told they had 'bronchitis', and in the rest the wheezing was mainly attributed to smoking and chest colds. In five it had음 been attributed to pneumonia or pleurisy, in three to bronchiectasis, and in two to pneumoconiosis; no $\frac{3}{3}$

T A B L E I HISTORY

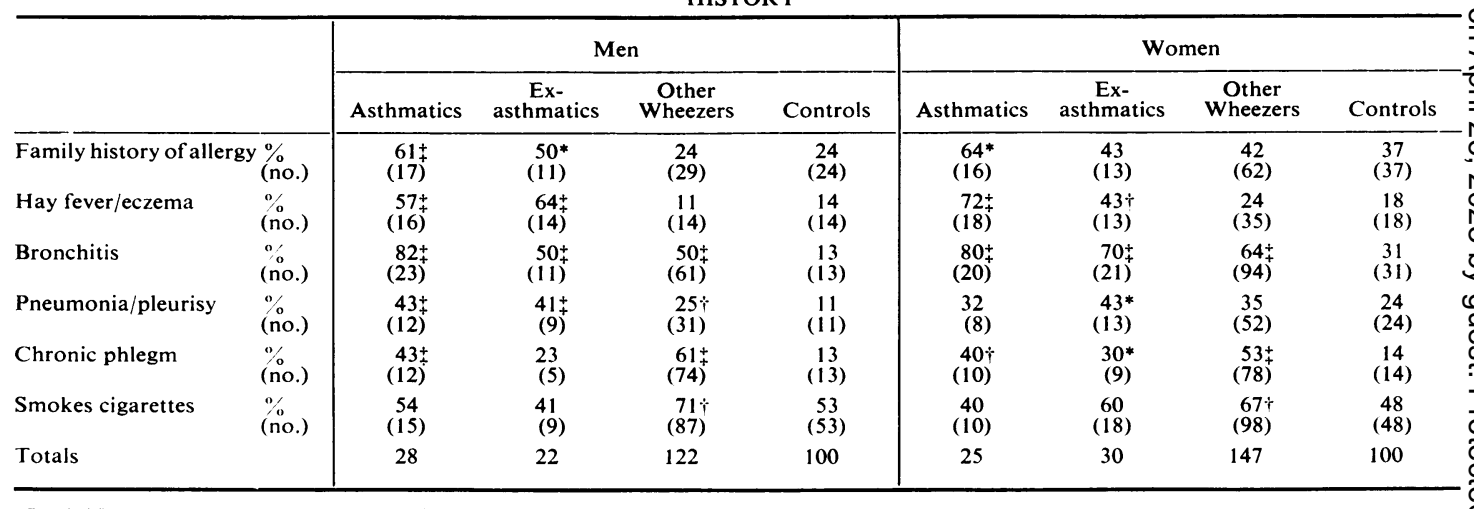

*P $<0.05 ; \quad+\mathrm{P}<0.01 ; \quad{ }_{+}^{+} \mathrm{P}<0.001$ in comparison with control group. 
other specific diseases or heart conditions were apparently involved. Except for 14 men and 21 women the 'other wheezers' had all wheezed during the previous 12 months.

Data relating to height, weight, and lung function are shown in Table II. The four groups did not differ with respect to age or height, but male asthmatics tended to weigh less than the other men. The initial $\mathrm{FEV}_{1}$ and $\mathrm{FVC}$ mean values were considerably lower in asthmatics than in the controls, and intermediate in ex-asthmatics and 'other wheezers'. The repeat results are shown as percentages of the initial values. Exercise produced a remarkably similar rise in $\mathrm{FEV}_{\mathbf{1}}$ and FVC, by about $3 \%$, in all groups except the asthmatics, in whom a marked fall occurred. This was completely reversed by salbutamol, which caused a further rise in the mean $F E V_{1}$ values of the other groups.

The results of the skin prick tests are summarized in Table III. The allergen of Dermatophagoides pteronyssinus was not available when the survey began, so the numbers tested against it are less than for the other allergens. A result is shown as positive if the weal was greater than that of the control solution. The asthmatics and ex-asthmatics tend to show allergic reactions whereas the 'other wheezers' resemble the control subjects in being mostly negative.

Table IV shows the serum IgE results; the mean levels are derived from logarithmic transformation of the data because of the distribution. Current asth- matics have significantly higher mean levels than the 'other wheezers' and controls, who are indistinguishable from each other in this respect.

\section{DISCUSSION}

CURRENT ASTHMATICS In view of the difficulties involved in defining asthma, a working definition was used, based on recent treatment for the condition. Questioning of these subjects did not elicit any reasons for doubting that the diagnosis would be upheld by most clinicians.

A personal and family history of allergic disease was usually present, as in the survey by Leigh and Marley (1967). This association between asthma and allergy was confirmed by the skin tests and IgE levels. Sensitivity to house dust and $D$. pteronyssinus is clearly a major factor in adult asthma, as in childhood (Sarsfield, 1974). Grass pollen sensitivity was also significantly commoner than in the control groups, but a reaction to Aspergillus was only occasionally encountered. Other allergens were not tested because they do not give good correlation between skin and nasal provocation tests (Brown, 1972). Furthermore, it has been shown by McCarthy (1973) that the allergens we have used give enough information to distinguish extrinsic from intrinsic asthma.

The initial FEV ${ }_{1}$ and FVC readings show that airflow was impaired even though no subject was in an asthmatic attack at the time. Thus the airways

T A B L E I I

ANTHROPOMETRIC AND LUNG FUNCTION DATA (MEAN $\because$ SE)

\begin{tabular}{|c|c|c|c|c|c|c|c|c|}
\hline & \multicolumn{4}{|c|}{ Men } & \multicolumn{4}{|c|}{ Women } \\
\hline & Asthmatics & $\begin{array}{c}\text { Ex- } \\
\text { asthmatics }\end{array}$ & $\begin{array}{c}\text { Other } \\
\text { Wheezers }\end{array}$ & Controls & Asthmatics & $\begin{array}{c}\text { Ex- } \\
\text { asthmatics }\end{array}$ & $\begin{array}{l}\text { Other } \\
\text { Wheezers }\end{array}$ & Controls \\
\hline Number & 28 & 22 & 122 & 100 & 25 & 30 & 147 & 100 \\
\hline Age (yr) & $31 \cdot 7 \pm 1 \cdot 2$ & $31 \cdot 8 \pm 1 \cdot 2$ & $33.6 \pm 0.6$ & $32 \cdot 3 \pm 0.7$ & $32 \cdot 0 \pm 1 \cdot 5$ & $32 \cdot 0 \pm 1 \cdot 1$ & $32.8 \div 0.6$ & $31 \cdot 7 \pm 0 \cdot 7$ \\
\hline Height (mm) & $1704 \pm 15$ & $1723 \pm 10$ & $1721 \pm 5$ & $1727 \pm 8$ & $1587 \pm 14$ & $1587 \div 12$ & $1597 \pm 5$ & $1600 \pm 6$ \\
\hline Weight (kg) & $68 \cdot 2 \pm 2 \cdot 5 \dagger$ & $75 \cdot 2 \pm 2 \cdot 4$ & $76 \cdot 6 \pm 1 \cdot 3$ & $75 \cdot 2 \pm 1 \cdot 0$ & $62 \cdot 2 \pm 2 \cdot 3$ & $58 \cdot 5 \pm 1 \cdot 5$ & $61 \cdot 9 \pm 1 \cdot 0$ & $60 \cdot 1 \pm 1 \cdot 1$ \\
\hline 1st $\mathrm{FEV}_{1}(1)$. & $2 \cdot 72 \pm 0 \cdot 20_{+}^{+}$ & $3 \cdot 37 \pm 0 \cdot 11^{*}$ & $3 \cdot 30 \pm 0.06 \pm$ & $3.69 \pm 0.06$ & ${ }_{(24)}^{1 \cdot 83 \pm 0 \cdot 15_{+}^{+}}$ & $2 \cdot 34 \pm 0 \cdot 10^{*}$ & $2 \cdot 30 \pm 0.05_{+}^{+}$ & $\begin{array}{c}2 \cdot 58 \pm 0.05 \\
(99)\end{array}$ \\
\hline $\begin{array}{l}\text { 1st FVC (1.) } \\
\text { After exercise } \\
\text { 2nd FEV }\end{array}$ & $4.27 \pm 0.17 \dagger$ & $4 \cdot 58 \pm 0.13$ & $4.46 \pm 0.06 t$ & $4.74 \pm 0.07$ & $2 \cdot 84 \pm 0 \cdot 14 \ddagger$ & $3 \cdot 16 \pm 0 \cdot 10$ & $3.04 \pm 0.05_{+}^{+}$ & $3.30 \pm 0.05$ \\
\hline $\begin{array}{l}\frac{2 n d}{1 s t F_{1}} \times 100 \\
\text { 2nd FVC }\end{array}$ & ${ }_{(27)}^{94 \cdot 3} 2 \cdot 2 \div 1$ & $\underset{(21)}{103 \cdot 2 \div 1 \cdot 5 \quad 1}$ & $\begin{array}{c}103 \cdot 2 \pm 0 \cdot 7 \\
(117)\end{array}$ & $\frac{103 \cdot 0 \underset{(95)}{ \pm} 0.6}{}$ & $91 \cdot 6 \underset{(23)}{+2} 2 \cdot 6_{+}^{+} 1$ & $103 \cdot 2+1 \cdot 3$ & $\begin{array}{c}103 \cdot 1+9 \\
(140)\end{array}$ & $\begin{array}{c}102 \cdot 5+0 \cdot 5 \\
(95)\end{array}$ \\
\hline$\frac{1 \text { st FVC }}{100}$ & $96 \cdot 9 \pm 1 \cdot 2+1$ & $103 \cdot 8 \pm 1 \cdot 2$ & $102 \cdot 8=0.5 \quad 1$ & $103 \cdot 0 \pm 0.4$ & $97 \cdot 4 \div 2 \cdot 2+1$ & $103 \cdot 5 \pm 3 \cdot 3$ & $103.2 \pm 0.7$ & $102 \cdot 3 \pm 0 \cdot 4$ \\
\hline $\begin{array}{l}\text { After Salbutamol } \\
\text { 3rd FEV }\end{array}$ & & & & & & & & \\
\hline 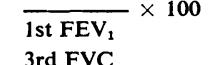 & $108 \cdot 1 \pm 2 \cdot 1$ & $105 \cdot 6 \pm 1 \cdot 7$ & $107 \cdot 3 \pm 0.9$ & $105 \cdot 1 \pm 0 \cdot 7$ & $\left.\right|_{(24)} ^{114 \cdot 8+4 \cdot 5 t}$ & ${ }_{(28)}^{110 \cdot 6 \pm 2 \cdot 4 \dagger}$ & $\underset{(146)}{107 \cdot 9 \pm 1 \cdot 0}$ & $\begin{array}{c}105 \cdot 6 \pm 0 \cdot 7 \\
(98)\end{array}$ \\
\hline$\frac{3 \mathrm{rV}}{1 \mathrm{st} F \mathrm{FV}} \times 100$ & $104 \cdot 1 \pm 1 \cdot 6$ & $101 \cdot 5 \pm 1 \cdot 2$ & $103.9 \pm 0.6$ & $102 \cdot 8 \pm 0 \cdot 4$ & $105 \cdot 2 \pm 2 \cdot 0$ & $108 \cdot 8 \pm 5 \cdot 0^{*}$ & $104 \cdot 3 \pm 0.6^{*}$ & $102 \cdot 3 \pm 0 \cdot 6$ \\
\hline
\end{tabular}

${ }^{*} \mathrm{P}<0.05 ; \quad+\mathrm{P}<0.01 ; \quad+\mathrm{P}<0.001$ in comparison with control group (pooled variances used for significance tests).

Numbers are shown in parentheses where the whole group did not participate. 
T A B L E I I I

RESULTS OF SKIN TESTS

\begin{tabular}{|c|c|c|c|c|c|c|c|c|}
\hline & \multicolumn{4}{|c|}{ Men with Positive Skin Tests } & \multicolumn{4}{|c|}{ Women with Positive Skin Tests } \\
\hline & Asthmatics & $\begin{array}{c}\text { Ex- } \\
\text { asthmatics }\end{array}$ & $\begin{array}{c}\text { Other } \\
\text { Wheezers }\end{array}$ & Controls & Asthmatics & $\begin{array}{c}\text { Ex- } \\
\text { asthmatics }\end{array}$ & $\begin{array}{c}\text { Other } \\
\text { Wheezers }\end{array}$ & Controls \\
\hline \begin{tabular}{ll|} 
House dust & $\%+$ \\
$150 \%$ w/v & (no.) \\
D. farinae & $\%++$ \\
$1 \%$ w/v & (no.) \\
D. pteronyssinus & $\%++$ \\
$1 \%$ w/v & (no.) \\
Grass pollen & $\%+$ \\
B2 $2.5 \%$ w/v & (no.) \\
Aspergilli M2 & $\%+$ \\
$5 \%$ w/v & (no.) \\
Any allergen & $\%++$ \\
\multicolumn{2}{c}{ No. tested for D. pteronyssinus } \\
Other allergens
\end{tabular} & $\begin{array}{c}82 \ddagger \\
(23) \\
82 \ddagger \\
(23) \\
74 \ddagger \\
(17) \\
61 \ddagger \\
(17) \\
7 \\
(2) \\
89 \ddagger \\
(25) \\
23 \\
28\end{array}$ & $\begin{array}{l}73 \ddagger \\
(16) \\
73 \ddagger \\
(16) \\
75 \ddagger \\
(15) \\
41 \dagger \\
(9) \\
14^{*} \\
(3) \\
86 \ddagger \\
(19) \\
20 \\
22\end{array}$ & $\begin{array}{l}18 \\
(22) \\
18 \\
(22) \\
16 \\
(18) \\
7 \\
(8) \\
2 \\
(2) \\
24 \\
(29) \\
111 \\
122\end{array}$ & $\begin{array}{l}17 \\
(17) \\
17 \\
(17) \\
15 \\
(15) \\
14 \\
(14) \\
3 \\
(3) \\
25 \\
(25) \\
99 \\
100\end{array}$ & $\begin{array}{c}64 \ddagger \\
(16) \\
60 \ddagger \\
(15) \\
75 \ddagger \\
(15) \\
48 \ddagger \\
(12) \\
8 \\
(2) \\
68 \ddagger \\
(17) \\
20 \\
25\end{array}$ & $\begin{array}{c}33^{*} \\
(10) \\
40 \ddagger \\
(12) \\
19 \\
(4) \\
27 \\
(8) \\
3 \\
(1) \\
40 \\
(12) \\
21 \\
30\end{array}$ & $\begin{array}{c}21 \\
(31) \\
17 \\
(25) \\
16 \\
(19) \\
14 \\
(21) \\
3 \\
(4) \\
25 \\
(37) \\
122 \\
147\end{array}$ & $\begin{array}{c}14 \\
(14) \\
12 \\
(12) \\
15 \\
(13) \\
12 \\
(12) \\
5 \\
(5) \\
27 \\
(27) \\
87 \\
99\end{array}$ \\
\hline
\end{tabular}

T A B L E I V

DISTRIBUTION OF SERUM IgE LEVELS

\begin{tabular}{|c|c|c|c|c|c|c|c|c|c|}
\hline & & \multicolumn{8}{|c|}{ Number of Subjects in Groups } \\
\hline \multicolumn{2}{|c|}{ IgE Levels } & \multicolumn{4}{|c|}{ Men } & \multicolumn{4}{|c|}{ Women } \\
\hline $\mathrm{u} / \mathrm{ml}$ & $\underset{\mathrm{u} / \mathrm{ml}}{\log }$ & Asthmatics & $\begin{array}{c}\text { Ex- } \\
\text { asthmatics }\end{array}$ & $\begin{array}{c}\text { Other } \\
\text { Wheezers }\end{array}$ & Controls & Asthmatics & $\begin{array}{c}\text { Ex- } \\
\text { asthmatics }\end{array}$ & $\begin{array}{c}\text { Other } \\
\text { Wheezers }\end{array}$ & Controls \\
\hline $\begin{array}{r}3162+ \\
1000-3161 \\
316-999 \\
100-315 \\
31.6-99 \\
10.0-31.5 \\
3.2-9.9 \\
1.0-3.1 \\
0.3-0.9\end{array}$ & $\begin{array}{l}3.5+ \\
3.0- \\
2.5- \\
2.0- \\
1.5- \\
1.0- \\
0.5- \\
0.0- \\
0.5-\end{array}$ & $\begin{array}{l}1 \\
4 \\
5 \\
3\end{array}$ & $\begin{array}{l}2 \\
2 \\
3 \\
5 \\
4\end{array}$ & $\begin{array}{r}1 \\
7 \\
21 \\
23 \\
27 \\
12 \\
8\end{array}$ & $\begin{array}{r}2 \\
1 \\
6 \\
15 \\
18 \\
19 \\
2 \\
11 \\
2\end{array}$ & $\begin{array}{l}1 \\
5 \\
5 \\
2 \\
1 \\
1 \\
1\end{array}$ & $\begin{array}{l}1 \\
1 \\
5 \\
3 \\
4 \\
1 \\
1\end{array}$ & $\begin{array}{r}2 \\
5 \\
17 \\
26 \\
21 \\
6 \\
11 \\
3\end{array}$ & $\begin{array}{r}2 \\
4 \\
11 \\
17 \\
13 \\
5 \\
8 \\
2\end{array}$ \\
\hline \multicolumn{2}{|c|}{$\begin{array}{l}\text { Mean IgE }(\mathrm{u} / \mathrm{ml}) \text { derived } \\
\text { from log data }\end{array}$} & $250 \cdot 1 \dagger$ & $112 \cdot 0$ & $36 \cdot 6$ & $41 \cdot 6$ & $127 \cdot 5 \dagger$ & $60 \cdot 6$ & $32 \cdot 3$ & $35 \cdot 2$ \\
\hline
\end{tabular}

obstruction of asthma has a chronic as well as an episodic component, as noted in the Finnish survey of Alanko (1970). The lower mean weight of the male asthmatics might indicate some effect of asthma on general health and nutritional state.

Exercise produces airways obstruction, maximal after a short interval, in asthmatic patients (Jones, Buston and Wharton, 1962; Anderson, Connolly and Godfrey, 1971). This effect was characteristic of the asthmatics but not of the other groups in the study.

EX-ASTHMATICS This group was probably incomplete in that events in early childhood may not always have been known and reported by the subjects concerned. Thus the results obtained do not necessarily apply to persons whose asthma occurred only in infancy.

The ex-asthmatics showed greater allergic tendencies than the controls, especially among the men. This is apparent from the personal and family history, skin tests, and mean IgE levels, though for these the differences were not statistically significant.

Their initial FEV 1 values showed some evidence of chronic impairment of air-flow. Exercise produced an effect indistinguishable from that in the controls, 으 namely, an increase in both FEV 1 and FVC of about $3 \%$. This contrasts with the findings by Jones and? Jones (1966) of a fall in $\mathrm{FEV}_{1}$ after exercise in eight. ex-asthmatics. The apparent discrepancy may be dueo to the selected nature of the latter group, to their lower mean age, or to a difference in methodology, 음 since the subjects ran for 8 minutes, and the post- $\rightarrow$ exercise $\mathrm{FEV}_{1}$ was repeated at minute intervals untilㅡㅡㄹ a minimum value was obtained.

'OTHER WHEEZERs' It was anticipated that a group of persons would give a history of wheezing withw breathlessness and in the absence of a cold while denying that they had asthma. If asthma merges withe chronic bronchitis in a spectrum of chronic obstruc-D tive lung disease, it might be expected that this group would show asthmatic characteristics to a greaterdegree than the control subjects.

There is a clear indication, derived from persona and family history, skin tests and IgE levels, that these 
'other wheezers' were no more marked by allergic tendencies than the control population. In this respect, and in their response to exercise, they were quite different as a group from the asthmatic subjects. While they may include a few undiagnosed cases of asthma, these can hardly be numerous in view of the overall results. The question therefore arises as to the cause of their wheezing.

In a very small number the wheezing was attributed to a specific condition, or it had occurred on only one or two occasions. The vast majority of subjects gave a history which, though differing in degree, was remarkably similar. They were usually smokers, claimed to be 'chesty', and had some chronic cough and sputum. Most of them had never consulted a doctor about their wheezing, and those who had were told that it was due to 'bronchitis' or smoking. Their lung function tended to be impaired at rest, the mean $F V_{1}$ and $F V C$ being lower than those of the controls. Thus they seem, for the most part, to have the features of chronic bronchitis, though not always to the degree necessary to qualify for that diagnosis. To what extent their symptoms will progress to the overt disease can be discovered only by follow-up studies.

CONTROLS The control group was a sample of persons who gave no history suggestive of asthma. The majority of this group had no personal or family history of allergic disease, and had not suffered from bronchitis or chronic respiratory symptoms. They were therefore presumed to be healthy from a respiratory point of view.

This assumption is confirmed by the regression equations of lung function on height and age derived from non-bronchitic men by Cotes et al. (1966) and from the two studies of Lowe et al. (1968). When applied to the present data, these equations predict mean $F V_{1}$ values of $3 \cdot 79,3 \cdot 93$, and 3.781 . respectively, and mean FVC values of $4 \cdot 72,4 \cdot 90$, and $4 \cdot 741$. The mean FEV 1 (3.69 1.) and FVC (4.74 1.) obtained for the control men are not significantly different from the predicted values derived from two of these studies.

On average their air-flow increased slightly after exercise, in contrast to the slight decrease which tends to occur in healthy children (Burr, Eldridge, and Borysiewicz, 1974). The inhalation of salbutamol caused the mean $F E V_{1}$ to rise further in both men and women. Thus it seems that air-flow resistance in healthy adults may be diminished slightly by exercise or bronchodilator drugs.

\section{CONCLUSIONS}

As a group, subjects receiving treatment for asthma differ from others in having impaired air-flow at rest, a fall in $\mathrm{FEV}_{1}$ and FVC after exercise, and a much greater prevalence of allergic characteristics.

There is within the population a much larger group of young adults who wheeze, mostly without coming under medical attention, and who do not seem to have asthma. Their lung function tends to be impaired and many of them have some degree of chronic bronchitis.

The results of this survey support the conventional clinical distinction between asthma and chronic bronchitis rather than the view that they should be regarded as aspects of chronic obstructive lung disease.

We thank the general practitioners of Caerphilly for access to their patients, Dr. J. E. Cotes and Dr. D. A. Williams for advice, Dr. P. J. Roylance and Bencard Ltd for antigen preparations, and Mr. H. Owen for laboratory help.

\section{REFERENCES}

Alanko, K. (1970). Prevalence of asthma in a Finnish rural population. Scandinavian Journal of Respiratory Diseases, Supplement, 76, p. 59.

Anderson, S. D., Connolly, N. M., and Godfrey, S. (1971). Comparison of bronchoconstriction induced by cycling and running. Thorax, 26, 396.

Brown, H. M. (1972). Prognosis of asthma. Lancet, 1, 1182.

Burr, M. L., Eldridge, B. A., and Borysiewicz, L. K. (1974). Peak expiratory flow-rates before and after exercise in schoolchildren. Archives of Disease in Childhood, 49, 923.

Burrows, B., Niden, A. H., Barclay, W. R., and Kasik, J. E. (1965). Chronic obstructive lung disease. I. Clinical and physiologic findings in 175 patients and their relationship to age and sex. American Review of Respiratory Diseases, 91, 521.

Ciba Guest Symposium (1959). Terminology, definitions and classification of chronic pulmonary emphysema and related conditions. Thorax, 14, 286.

Cotes, J. E., Rossiter, C. E., Higgins, I. T. T., and Gilson, J. C. (1966). Average normal values for the forced expiratory volume in white Caucasian males. British Medical Journal, 1, 1016.

Ford, R. M. (1969). Aetiology of asthma: a review of 11,551 cases (1958-1968). Medical Journal of Australia, 1, 628.

Jones, R. H. T. and Jones, R. S. (1966). Ventilatory capacity in young adults with a history of asthma in childhood. British Medical Journal, 2, 796.

Jones, R. S., Buston, M. H., and Wharton, M. J. (1962). The effect of exercise on ventilatory function in the child with asthma. British Journal of Diseases of the Chest, 56, 78.

Leigh, D. and Marley, E. (1967).' Bronchial Asthma: A Genetic, Population and Psychiatric Study. Pergamon Press, Oxford.

Lowe, C. R., Pelmear, P. L., Campbell, H., Hitchens, R. A. N., Khosla, T., and King, T. C. (1968). Bronchitis in two integrated steel works. I. Ventilatory capacity, age, and physique of non-bronchitic men. 
British Journal of Preventive and Social Medicine, 22, 1.

McCarthy, O. R. (1973). Selection of skin tests in asthma. British Journal of Diseases of the Chest, 67, 238.

Medical Research Council Committee on the Aetiology of Chronic Bronchitis (1965). Definition and classification of chronic bronchitis. Lancet, 1, 775.

Mitchell, R. S. and Filley, G. F. (1964). Chronic obstructive bronchopulmonary disease. I. Clinical features. American Review of Respiratory Diseases, 89, 360.

Nye, L., Merrett, T. G., Landon, J., and White, R. (1975). A detailed investigation of circulating IgE levels in a normal population. Clinical Allergy, 5, 13.

Porter, R. and Birch, J. (1971). Identification of asthma.
Ciba Foundation Study Group No. 38, p. 174. Churchil Livingstone, Edinburgh and London.

Sarsfield, J. K. (1974). Role of house-dust mites in childhood asthma. Archives of Disease in Childhood

Scadding, J. G. (1971). The definition of asthma: generaf̂ introduction. In Identification of Asthma: CibaFoundation Study Group No. 38, edited by R. Porte? and J. Birch, p. 13. Churchill Livingstone, Edinburgh and London.

Requests for reprints to: Dr. M. L. Burr, MRC Epi demiology Unit (South Wales), 4 Richmond Road Cardiff CF2 3AS. 